\title{
Functionalized Bark for Recycled Polypropylene-Based Composites
}

\author{
Anrijs Verovkins ${ }^{1}$, Brigita Neiberte ${ }^{1}$, Galia Shulga', Viktor Shapovalov², \\ Andrej Valenkov ${ }^{2}$ \\ 1 - Latvian State Institute of Wood Chemistry, Address: 27 Dzerbenes Str., Riga, LV-1006, Latvia. \\ 2 - Institute of Mechanics of Metal-Polymer Systems, NAS of Belarus, Address: 32 a Kirov Str., \\ 246050, Gomel, Belarus
}

\begin{abstract}
A new method for the modification of the bark surface using N,N-diethyl-2,3-epoxypropylamine (DEEPA) was developed. As a result, the part of the bark phenolic hydroxyl groups were replaced with amine groups. The conditions of the modification were found, and the modified products were analysed. The different amount of the introduced amino groups in hardwood and softwood bark was gained by the various contents of lignin in the wood species. The recycled propylene-based composites filled with the modified bark were characterised by higher mechanical parameters in comparison with the composites filled with unmodified bark. The differences in the mechanical properties of the polymer composites filled with softwood - pine (Pinus sylvestris) bark and hardwood - grey alder (Alnus incana) bark has been established.
\end{abstract}

Keywords - composite, epoxyamination, modified bark, secondary polypropylene.

\section{INTRODUCTION}

Nowadays one of the parameters of social welfare is the produced amount of waste. Due to developing economical situation in the world within the last decades also production of municipal and hazardous waste has increased rapidly. Waste management depends on the legislation and waste management infrastructure in each country. In any case there are always problems with waste deposition and directly with leachate.

Logging and mechanical processing of wood are well developed in Latvia. The annual output of these industries is about 6.8 million solid $\mathrm{m}^{3}$ of different types of lignocellulosic by-products, including bark. Wood bark normally constitutes a considerable volume of a $\log$ - from $10 \%$ to $20 \%$, depending on the wood species and log diameter [1]. This lignocellulosic by-product is commonly burned up or stored, not finding much more rational utilisation.

Polyolefins such as polyethylene and polypropylene are the main constituents of polymeric municipal solid wastes. A perspective practice for recovering these polymers may be their processing together with the use of lignocelluloses as reinforcement agents [2], [3]. At the same time, the wood fillers in polymer composites have several disadvantages, the main of which being their low compatibility with the synthetic polymeric matrix.

One of the possible modification ways of a bark as a filler for the composite materials is the replacement of phenolic hydroxyl groups of lignin in the lignocellulosic structure of the bark with amine groups. It is known that lignin nitrogen-containing derivatives are obtained by a variety of methods [4] [6]. In our previous work, carried out at the Latvian State Institute of Wood Chemistry, various lignins have been aminated with N,N-diethyl-2,3epoxypropylamine (DEEPA) [7]. The content of nitrogen in the obtained amino derivatives is 1.7$3.8 \%$. A good correlation is observed between the nitrogen content in aminolignin and the content of phenolic groups in the initial lignin.

The aim of the present study was to apply the developed method of lignin modification with DEEPA for the modification of bark, taking into account the presence of lignin, and to study mechanical properties of the obtained polymer composites filled with the modified bark.

\section{MATERIALS AND METHODS}

\section{Raw material}

The initial pine (Pinus sylvestris) and grey alder (Alnus incana) bark (Table 1) were used as a filler for the wood-polymer composites. At first, they were milled, using "Retsch SM-100" cutting mills, for obtaining the filler particles with a size $<500 \mathrm{mk}$, and then modified. The thermoplastic polymer matrix used was a powder recycled polypropylene (PP). The content of the wood filer in the wood-polymer composites does not exceed 50 mass \%.

TABLE 1.

CHEMICAL COMPOSITION OF INITIAL BARK [8]

\begin{tabular}{|c|c|c|c|c|c|}
\hline \multirow[b]{2}{*}{$\begin{array}{l}\text { Bark } \\
\text { species }\end{array}$} & \multirow[b]{2}{*}{$\begin{array}{l}\text { Cellulose } \\
(\%)\end{array}$} & \multirow[b]{2}{*}{$\begin{array}{l}\text { Klason } \\
\text { lignin } \\
(\%)\end{array}$} & \multicolumn{2}{|c|}{ Extractives soluble } & \multirow[b]{2}{*}{$\begin{array}{l}\text { Ash } \\
(\%)\end{array}$} \\
\hline & & & $\begin{array}{l}\text { In } \\
\text { water } \\
(\%)\end{array}$ & $\begin{array}{l}\text { In } \\
\text { organic } \\
\text { solvent } \\
(\%)\end{array}$ & \\
\hline Pine & 18.1 & 51.2 & 4.4 & 7.9 & 2.4 \\
\hline $\begin{array}{l}\text { Grey } \\
\text { alder }\end{array}$ & 20.7 & 36.5 & 5.6 & 15.1 & 4.6 \\
\hline
\end{tabular}




\section{Chemical modification}

The amination reagent was synthesised from diethylamine and epichlorohydrin according to the two-stage advanced method by Zakis [9]. At the first stage, $2 \mathrm{ml}$ of water was added to diethylamine $(71 \mathrm{ml}, 0.69 \mathrm{M})$ and epichlorohydrin $(54 \mathrm{ml}, 0.70 \mathrm{M})$ to initiate the reaction. The mixture was stirred for $5-$ $6 \mathrm{~h}$ at a temperature of $28-30^{\circ} \mathrm{C}$ (cooling in water bath) to form diethylamino-oxy-propoxy-chloride. At the second stage, sodium hydroxide $(32.5 \mathrm{~g}, 0.82 \mathrm{M})$ and water $(53 \mathrm{ml})$ were added for dissolving the residue to form DEEPA.

\section{Testing of composites}

The samples were prepared by the extrusion method on an extruder "RHEOCORD 90" (HAKKE, Germany) at the temperature $170-180^{\circ} \mathrm{C}$ as well as by moulding under a pressure in a casting machine at a temperature of $180^{\circ} \mathrm{C}$. The mechanical tests were carried out in a universal machine "Instron" (USA). The surface structure of the obtained composites was examined on a scanning electron microscope Tesla (Czech Republic).

\section{RESULTS AND DISCUSSION}

\section{Bark modification}

For many modes of the chemical modification of lignin, hydroxyl groups play the leading role [10], [11]. The heating of bark with DEEPA aqueous solution results in the formation of bark amino derivatives containing 2-hydroxy-3-diethyl-aminepropoxy groups.

Optimum amination conditions were achieved at a modulus of $1: 15$ (bark : water solution), a reagent mass ratio of 1:1.5 (bark : DEEPA), a reaction time of $1 \mathrm{~h}$, and a temperature of $98 \pm 2^{\circ} \mathrm{C}$, with stirring.

The highest yield and N-content of amino derivatives were, when the active component DEEPA was separated from the whole synthesis mixture.

The interaction between lignin and the modifier may be represented according to the mechanism shown in scheme:

$$
\rightarrow \text { Bark-Lignin }-\mathrm{OH}+\mathrm{H}_{2} \mathrm{C}-\mathrm{CH}-\mathrm{CH}_{2} \mathrm{~N}\left(\mathrm{C}_{2} \mathrm{H}_{5}\right)_{2} \rightarrow
$$

Our study has revealed that, on the average, up to $3 \%$ of nitrogen may be introduced in the bark (Table 2 ). It is supposed that the different amount of the introduced amino groups in hardwood and softwood is gained by the various contents of lignin in pine bark and grey alder bark (Table 1). With increasing the lignin content, the amount of the introduced amino groups grows.
TABLE 2.

NITROGEN CONTENT IN BARK DEPENDING ON MODIFICATION CONDITIONS

\begin{tabular}{|l|l|l|l|l|}
\hline \multirow{2}{*}{$\begin{array}{l}\text { Bark } \\
\text { species }\end{array}$} & \multicolumn{2}{|l|}{ With all synthesis mixture } & \multicolumn{2}{l|}{ Active component DEEPA } \\
\cline { 2 - 5 } & $\begin{array}{l}\text { Yield of } \\
\text { N-polymer } \\
(\%)\end{array}$ & $\begin{array}{l}\text { N-content } \\
\text { in } \\
\text { N-polymer } \\
(\%)\end{array}$ & $\begin{array}{l}\text { Yield of } \\
\text { N-polymer } \\
(\%)\end{array}$ & $\begin{array}{l}\text { N-content } \\
\text { in } \\
\text { N-polymer } \\
(\%)\end{array}$ \\
\hline Pine & 76 & 3.04 & 135 & 3.84 \\
\hline $\begin{array}{l}\text { Grey } \\
\text { alder }\end{array}$ & 57 & 1.37 & 92 & 2.61 \\
\hline
\end{tabular}

\section{Bark-polymer composites}

The analysis of the physico-mechanical properties of the obtained polymer composites indicates that the composites filled with the amino-containing pine and grey alder bark, on the whole, are characterized by better physico-mechanical properties in comparison with those of the composites containing the unmodified bark (see Fig. 1-4). This demonstrates an increase in the tensile strength and the rupture deformation by $31-50 \%$ and $14-52 \%$, respectively, in comparison with those of the composite containing unmodified bark. At the same time, the values of modulus of elasticity and tangential modulus increase by $7-11 \%$ and $9-24 \%$, respectively. The elevated values of the composite deformation may testify the additional plasticizing effect of the modified bark due to the presence amino groups.

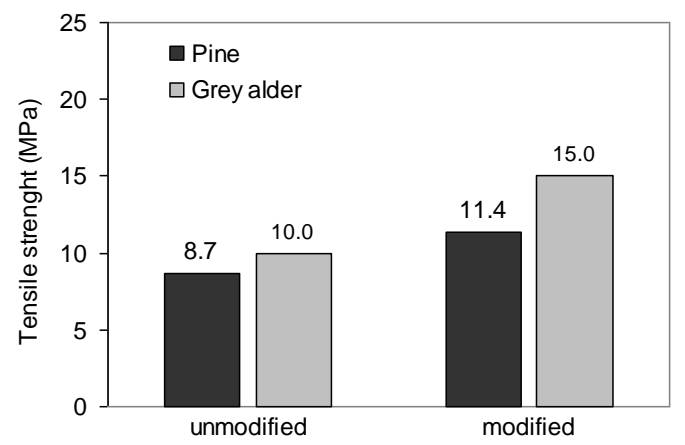

Fig. 1. Tensile strength of polymer composites filled with intial wood bark and modified ones

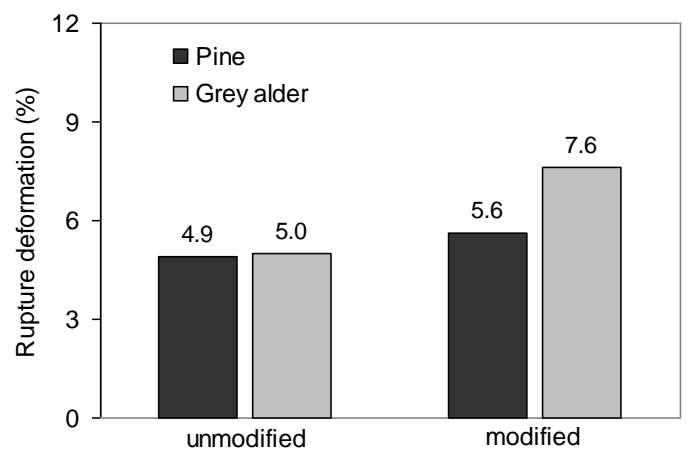

Fig. 2. Rupture deformation of polymer composites filled with initial wood bark and modified ones 


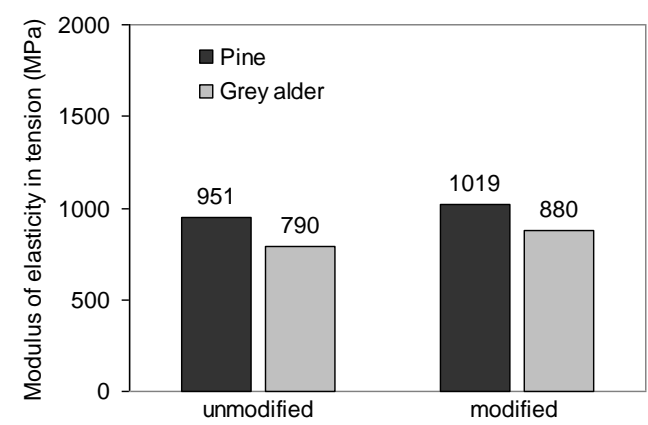

Fig. 3. Modulus of elasticity of polymer composites filled with initial and modified wood bark

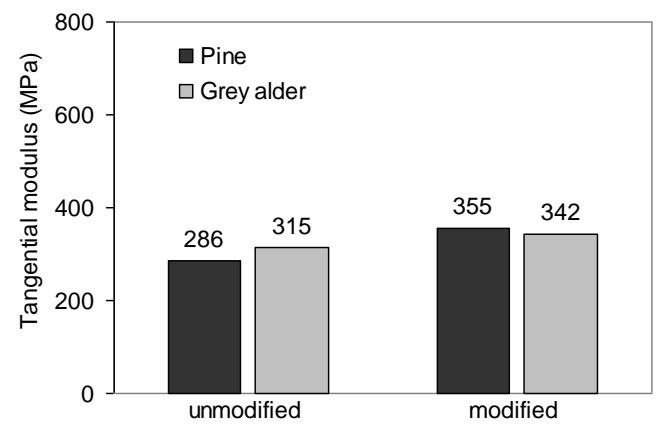

Fig. 4. Tangential modulus of polymer composites filled with intial wood bark and modified ones

The results show that the composite materials filled with modified grey alder bark are characterised by higher physico-mechanical properties than those filled with modified pine bark (see Fig. 1, Fig. 2 and Fig. 4). It is supposed that the worsening of mechanical properties for the softwood filler may be governed by the enhanced content of resins in pine wood, which can negatively influence the compatibility of the polymer matrix with the filler. The morphology of the polypropylene composite filled with the aminated pine bark was examined by SEM. The microphotography given in Fig. 5 demonstrates a good homogenity of the obtained composite structure.

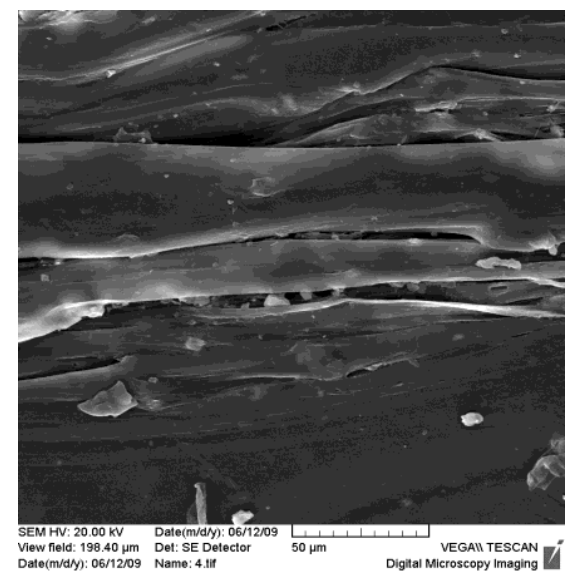

Fig. 5. Structural consolidation of filler particles in the composite, containing pine bark modified with DEEPA $(50 \%$ recycled polyprolylene $/ 50 \%$ modified pine bark)

The conducted moisture sorption study at a relative humidity of $98.9 \%$ during 90 days showed that a moisture sorption of $4.0-5.0 \%$ was characteristic for the composites filled with the modified bark both hardwood and softwood. The free hydroxyl groups presented in the modified bark were responsible for the absorption of water that decreased the mechanical properties of the obtained polymer composites. Our future investigation will be directed to the improvement of hardwood and softwood bark modification with the aim of obtaining the propylenebased composites with a lower moisture sorption.

\section{CONCLUSION}

A new method for the modification of the bark surface using DEEPA was developed. The optimal conditions of the bark modification were found, and the modified lignocellulosic products were obtained and analysed. The content of nitrogen in the modified bark was $1.7-3.8 \%$. It is established that the application of the modified bark increases up to $50 \%$ of the tensile strength of the polymer composites in comparison with those containing unmodified bark as a filler. At the same time, the modified bark of hardwood effects more favourable on the composite mechanical properties than the modified softwood bark. The morphological study of the polypropylene composite filled with the aminated pine bark testifies a good homogenity of the obtained composite's structure.

\section{REFERENCES}

[1] Fengel D., Weneger G. Wood - Chemistry, Utrastructure, Reactions. Germany: Verlag Kessel, 2003, 613. pp.

[2] Bledzki A.I., Letman M., Shapovalov V.M., Tavroginskaya M.G. Physico-mechanical and technological characteristics of polypropylene and wood-based composites, In: The 5th Global Wood and Natural Fibre Composites Symposium, Kassel, Germany, 2004, pp. 25.1-25.5.

[3] Shulga G., Neiberte B., Verovkins A., Laka M., Chernyavskaya S., $\quad$ Shapovalov V., $\quad$ Valenkov A., Tavroginskaya $\mathrm{M}$. The new polymer composites integrating modified wood originated products. In: Proceedings of the International Conference Italic-5, Science and Technology of Biomass, Advances and Challenges, Varenna, Italy, September 1-4, 2009. pp. 185-188.

[4] Wiest E.G., Balon W.J. Reaction of unsulfonated lignin, formaldehyde and secondary amines and product. U.S. Patent 2,709,696, 1955.

[5] Mikawa H., Sato K., Takasaki C., Ebisawa K. Studies on the cooking mechanism of wood. XV. Mannich reaction on lignin model compounds and the estimation of the amount of the simple guaiacyl nucleus in thiolignin. Bull. Chem. Soc. 29, 1956, pp. 259-265.

[6] Falkehag S.I., Diling P. Process for producing cationic lignin amines. U.S. Patent 3,718,639, 1973.

[7] Zakis G., Neiberte B. Amino derivatives of lignins. 3. Reaction of lignins with diethylepoxypropylamine. Latvian Journal of Chemistry, 4, 2000, pp. 89-96

[8] Verovkins A., Neiberte B., Sable I., Zakis G., Shulga G. Chemical composition of Latvian characteristic wood species bark. Latvian Journal of Chemistry, 2, 2008, pp. 195-201.

[9] Zakis G., Neiberte B., Verovkins A., Smogol V. Amino derivatives of lignin. 4. Amination of lignin in composition of lignocellulose complex - obtaining of bile acid sorbent. Latvian Journal of Chemistry, 3, 2006, pp. 287-291.

[10] Sarkanen K.V., Ludwig C. Lignins: Occurrence, Formation, Structure and reactions. New York: Eds. H. John Wiley \& Sons, Inc., 1971, 916. pp.

[11]Rowell R.M. Handbook of Wood Chemistry and Wood Composites. Madison, USA: Taylor \& Francis, 2005, 473. pp. 